\title{
The Evaluation of Gold Contacts
}

\author{
RELATIONSHIP BETWEEN TESTING METHODS \\ AND PERFORMANCE IN SERVICE
}

\author{
The International Conferences on Electric Contact Phenomena \\ organised by the Illinois Institute of Technology have become an \\ annual feature in their field. At the sixth meeting, held in Chicago \\ in June, a number of papers were concerned with the design and \\ performance of gold contacts and the evaluation of testing methods.
}

Gold is the noble metal most frequently used for contacts in electronic systems today, and it is estimated that something over 100 tons are absorbed annually by the electronics industry throughout the world. The value of this amount of gold is of course very greatly exceeded by the ultimate value of the equipment in which it is used, and there is thus ample justification for the many investigations that have been undertaken into its performance and its methods of testing.

A great proportion of the gold used as contacts is of course applied by electrodeposition, and a paper by R. G. Baker of Bell Telephone Laboratories, Murray Hill, New Jersey, set out to evaluate gold electrodeposits for use in dry circuits.

For these applications, gold may be unalloyed and soft or lightly alloyed and hard. The soft deposits of nearly pure gold are used to provide clean tarnishfree surfaces on parts which are to be joined by thermal compression bonding or by solderless wrapping, or which are required to retain their solderability during extended storage.

The harder deposits, measuring in the region of 110 to 140 V.P.H., containing usually up to 1 per cent of silver or cadmium, are widely used in what Baker calls "new generation" contacts, the "separable static connectors" needed in miniaturised sophisticated electronic equipment. Here the voltages, currents and contact forces are small and are usually insufficient to cause electrical, thermal or mechanical breakdown of any tarnish films that may be present. These are the so-called "dry contacts", shunned at one time by all right-thinking circuit designers.

It is not surprising that the design, fabrication and performance of the immaculate gold surfaces needed for these contacts-the heart of all electronic circuits-have received considerable attention during the last decade. Equally it has been necessary to develop methods for their evaluation. These are ably reviewed by Baker in his paper.

Nearly all investigations have indicated that the most important characteristic influencing the satis- factory performance of a gold deposit is its porosity. Ideally, the gold coating should be entirely pore-free, for wherever there is a pore there is a possibility that the underlying metal may be attacked and the corrosion products may spread out over the gold surface. In practice, some porosity must be accepted as inevitable due to such factors as imperfections in the underlying metal, variations in its roughness and general surface conditions, and departures from ideals of cleanliness and freedom from gas bubbles in the electrodeposition process. Baker considers the amount of porosity that can be safely tolerated is usually determined by engineering judgment and experience. One authority, for example, has suggested that a maximum of 4 pores per sq $\mathrm{cm}$ should be specified.

The Bell Telephone Laboratories have for many years set a maximum of 6 pores per square centimetre with no more than 4 per cent of the area having that pore density when tested immediately after gold plating. Over the years, gold deposits produced in the industry have successfully met this requirement. Several problems that have been found have usually been traced to too thin a gold deposit, poor surface preparation of the basis metal parts, or uncontrolled bath conditions.

\section{Accelerated Laboratory Tests}

The testing of deposits to establish the limits of allowable porosity (and the required minimum thickness of gold) is still a matter of controversy. At the Chicago conference, both Baker and Josef Kirchdorfer, of Weber Limited, Emmenbrücke, Switzerland (but with Ghielmetti Ltd of Solothurn when the paper was written) discussed the problem with some thoroughness. It is generally accepted that many accelerated laboratory tests, particularly those in which specimens are exposed to $\mathrm{H}_{2} \mathrm{~S}$ or flowers of sulphur, produce films very different in their characteristics from those formed in service environments, but the problem of devising any meaningfulmeasureof performanceremains largely unsolved. 
Kirchdorfer reports on the results of a series of comparative tests on plug contacts (with large wiping distances) as well as on relay-type butt contacts with low contact force, of the type discussed above, using various accelerated life tests and long-life tests in a non-air conditioned workshop atmosphere in Solothurn, Switzerland, and in an extremely humid environment where condensation occurred. The accelerated tests included exposure to damp atmospheres containing hydrogen sulphide, to humidity-saturated atmospheres containing sulphur dioxide, as well as to six other environments which have been proposed. The test results show, in Kirchdorfer's words, enormous differences and insufficient agreement with long time exposure. Moreover, they confirm the knowledge that any test method which does not simulate actual tarnishing sufficiently well may be applicable for a certain contact system, but will lead to entirely wrong results with another.

A smaller but equally important application for gold is on the contact surfaces of sliding contactssuch as in instrument slip rings-and in such static separable contacts as plug connectors where appreciable sliding is involved.

\section{Problems of Wear and Lubrication}

A most comprehensive review of the many studies which have been made on the mechanism of wear of both unlubricated and lubricated contact surfaces in these conditions was presented to the Conference by Morton Antler, of the Bell Telephone Laboratories at Columbus, Ohio.

Antler has shown that the sliding wear of gold may occur by one or more of three mechanisms involving adhesion, abrasion and brittle fracture respectively.

He claims that wear of sliding gold contacts, particularly when unlubricated, occurs mainly by an adhesive process involving the formation of a "prow". Whether or not this is of primary importance in all service applications, he has presented some most striking experimental evidence that prow formation is predominant when a very smooth rounded unlubricated gold or gold-rich alloy contact is first rubbed along a smooth gold surface under a load of a few grams. The prow is always composed of metal picked up from the long track on the flat member, and is harder than either original surface because of the extreme degree to which it is cold worked in its transfer and growth.

After a prow has formed, further rubbing often causes it to be removed either by back transfer to the original surface or, by general disintegration, to a powdery debris which is eventually brushed away and lost.

When a soft gold contact is rubbed along a rather harder flat, such as platinum, prow formation may be preceded by the formation of a preliminary smearcoating of gold from the soft rider. Eventually, however, this coating may be so hardened that it is picked up by the rider and begins to form a prow. An example of this is shown in the upper illustration.

It is possible in extreme instances for the track metal to be so hard that pick-up cannot occur. When for example a gold contact is rubbed along a rhodium plated surface no pick-up of rhodium can occur. Instead, the gold smears over the electrodeposited rhodium and on continued rubbing may transfer back with the formation of only a small gold prow, as shown in the lower picture. The wear is then concentrated entirely on the rider. Here seems to be an explanation of the widely-held belief that gold acts as its own lubricant when rubbed against a rhodium-plated surface.

Prow formation is, of course, only one factor influencing the wear of gold sliding contacts, and it is usually significant only in the early stages of unlubricated friction.

It may, however, be of prime importance in determining the performance of separable connectors which slide only short distances in their lifetimes. These are typically of the plug and socket type and will be expected to withstand 10 to 500 insertions and withdrawals for a pass length of 2 to $20 \mathrm{~mm}$, depending on design. They are thus not required to operate beyond the initial stages of wear. Prow formation is thus likely to be the only wear-mechanism involved; it is undesirable and when it occurs may interfere with the satisfactory operation of the contact.

Apart from using so hard a substance as rhodium plate as one of the mating surfaces, prow formation can be minimised by the use of various hard gold plates. Antler presents test results which indicate that gold alloys containing 0.15 per cent of nickel, 0.1 per cent cobalt, or 2.5 per cent cobalt with 1 per cent indium, with hardness values in the range from 190 to 134, can resist prow formation notably when used with a pure gold rider and show very little wear. He also points out that if the roughness of the contact surfaces exceeds a critical value, dependent on the load and the compositions of the components, prows will not form. The use of rough surfaces is not satisfactory as a general rule, however, since these are usually associated with porosity of the gold coating, with the consequent problems of tarnish and corrosion, to avoid which is the whole purpose of using gold. 
The wear of sliding gold contacts, particularly when unlubricated, occurs, according to Dr Morton Antler, mainly by an adhesive process involving the formation of a "prow". When a soft gold contact is rubbed along a somewhat harder surface such as platinum, prow formation may be preceded by the smearing of gold on to the flat surface. On repeated passes, however, this transferred metal may be so work-hardened that it is picked up by the rider and begins to form a prow
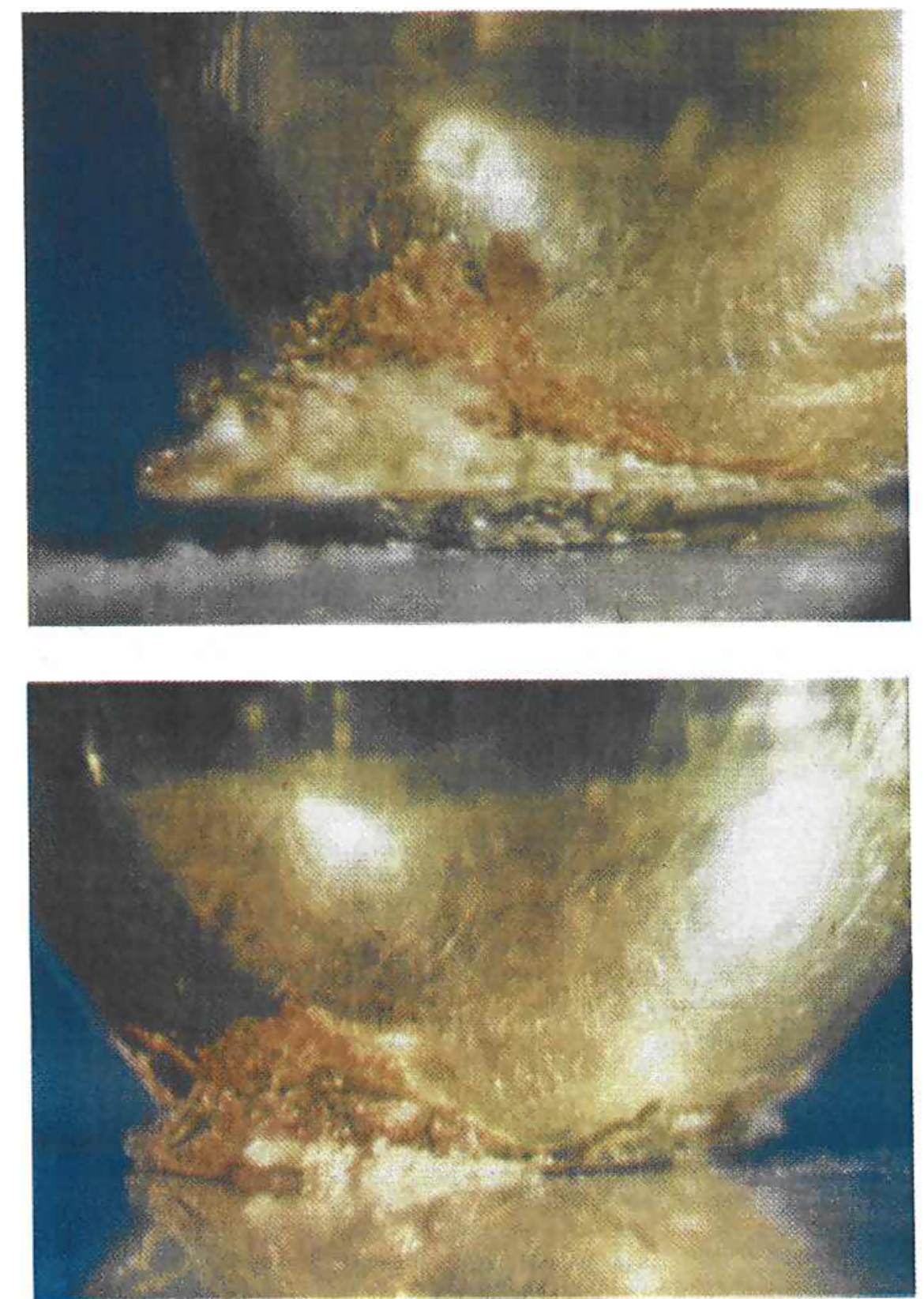

If the flat surface is much harder than the gold, as is the case with rhodium, a small amount of the gold may transfer back and forth between rider and flat with no prow formation and little wear resulting. (Direction of movement from left to right)

The other, and probably more extensively used, type of sliding contacts is that embracing instrument slip rings which slide for long distances, either continuously or intermittently. Providing the initial prow formation does not cause catastrophic damage, the equilibrium wear rate is the factor of prime interest to the designer.

Empirically, certain electrodeposited alloy golds having a hardness of 300 to 450 have been found to be unusually wear resistant. It is often said that very hard deposits wear poorly as compared with those of an intermediate hardness, but where this has been observed it is likely that the alloys were deposited on deformable substrates which allowed brittle fracture to occur.
Finally, the performance of all sliding contacts may be greatly improved by suitable lubrication. Although all lubricants in bulk are insulators, thin films of a lubricant having a suitable liquid phase permit asperities in the contact surfaces to make adequate contact through the film. The outstanding problem is said to be durability, that is keeping a supply of lubricant always available; but it would appear that it is equally important to avoid pick-up of solid dust particles and other air-borne contaminants. There is evidently still ample scope for design ingenuity in ensuring that the best use is made of the noble characteristics of gold and gold contacts.

J. C. C. 